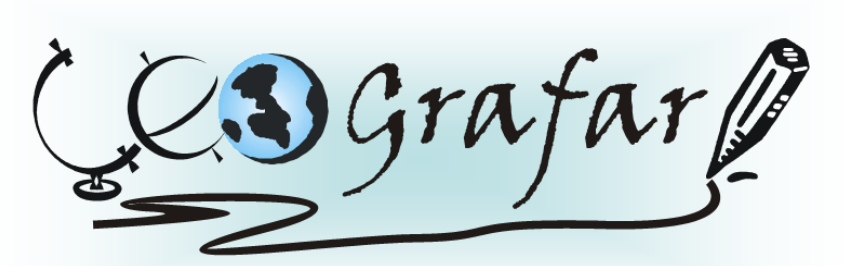

Revista Eletrônica do Programa de Pós-Graduação em Geografia - UFPR

SEÇÃo MultípliCE - Relato de doutorado sanduíche

\title{
CONTRIBUIÇÕES DO ESTÁGIO DE DOUTORADO SANDUÍCHE NA FORMAÇÃO ACADÊMICA: DESAFIOS E CONQUISTAS
}

\author{
HELENA MIDORI KASHIWAGI ${ }^{1}$
}

\begin{abstract}
RESUMO
Este artigo tem como objetivo apresentar as contribuições do estágio de Doutorado Sanduíche na formação acadêmica do estudante. Os estágios no exterior representam uma das parcerias internacionais entre Instituições brasileiras e estrangeiras oportunizadas pela Coordenação de Aperfeiçoamento de Pessoal de Nível Superior (CAPES). Com o objetivo de desenvolver atividades de pósgraduação brasileira no contexto mundial, a CAPES apóia o intercâmbio internacional, buscando-se a excelência do ensino da pós-graduação no país. As cotas de bolsas às Instituições de Ensino Superior são concedidas em função do conceito obtido na Avaliação Trienal da CAPES. Já as bolsas são concedidas aos estudantes com potencial científico para o desenvolvimento dos estudos propostos no exterior. Apresentam-se os desafios e conquistas como bolsista do Programa de Doutorado Sanduíche no Exterior (PDSE) durante o estágio realizado na Universidad Autónoma de Madrid. Na condição de precursora nessa modalidade de estágio no Programa de Pós-Graduação em Geografia da Universidade Federal do Paraná (UFPR), o compromisso tornou-se ainda maior. Superada todas as etapas seletivas da candidatura realizou-se o estágio entre os meses de abril a agosto de 2010, sob a orientação da Professora Salete Kozel (UFPR), no Brasil, e da coorientação do Professor Clemente Herrero Fabregat (UAM), na Espanha. Essa experiência no exterior proporcionou além da contribuição de novos referenciais teórico-metodológicos, o amadurecimento pessoal e a apreensão de novos valores culturais. Defendeu-se a tese em junho de 2011, selando os compromissos com o PDSE, a CAPES e a UFPR.
\end{abstract}

Palavras-Chave: Doutorado Sanduíche. Geografia. Espanha. CAPES.

\footnotetext{
${ }^{1}$ Prof ${ }^{\mathrm{a}}$ Drª ${ }^{\mathrm{a}}$ de Planejamento Urbano - Universidade Federal do Paraná; e-mail: helenamidori@ufpr.br
} 


\section{INTRODUÇÃO}

Este artigo tem a finalidade de apresentar as contribuições do estágio de Doutorado Sanduíche na formação acadêmica do estudante. A experiência de estudar no exterior possibilita o aprofundamento da pesquisa com novos referenciais conceituais e metodológicos sob o contexto mundial. Além da oportunidade de formar uma postura crítica e reflexiva sobre os conhecimentos na convivência e debates com pesquisadores de outras Instituições estrangeiras.

No Brasil uma das Instituições que concede bolsas de estudos para o exterior é a Coordenadoria de Aperfeiçoamento de Pessoal de Nível Superior (CAPES). Vinculada ao Ministério da Educação, a CAPES foi instituída pelo Decreto Federal n. 29.741 de 11 de julho de 1951 com o objetivo de assegurar a formação de especialistas e pesquisadores nos mais diversos ramos de atividade, visando o desenvolvimento econômico e social do país. A CAPES foi regulamentada pela Lei Federal n. 8405 de 9 de janeiro de 1992 e o Estatuto foi aprovado pelo Decreto Federal n. 6.316 de 20 de dezembro de 2007. A sede da CAPES está na cidade de Brasília - Distrito Federal.

Atualmente, a CAPES para complementar os esforços dos cursos de pósgraduação no Brasil concede bolsas de estudo no exterior por meio de Programas de Doutorado, Doutorado Sanduíche no Exterior (PDES), Estágio Pós-Doutoral, Estágio Sênior, Programa de Apoio a Eventos no Exterior (PAEX), Programa de Áreas Estratégicas e Institutos Nacionais de Ciência e Tecnologia, e, Grande Prêmio CAPES de Teses.

A realização de cooperações internacionais com Instituições estrangeiras por meio de acordos bilaterais vem possibilitando apoiar grupos de pesquisa brasileiros, bem como o financiamento de missões de trabalho (intercâmbio de professores), bolsas de estudo (intercâmbio de alunos), além de custear programas que fomentam projetos conjuntos de pesquisa entre grupos brasileiros e estrangeiros.

A intenção desse texto é apresentar um desses Programas que a CAPES mantém com o exterior: o PDSE. Esse Programa foi instituído recentemente pela 
Portaria Federal n. 96 de 27 de junho de 2011 e substituiu o antigo Programa de Doutorado no País com Estágio no Exterior (PDEE). Com esse novo programa de Doutorado Sanduíche no exterior ocorreram algumas mudanças como, por exemplo, a concessão de cotas de bolsas às Instituições de Ensino Superior (IES) com nota igual ou superior a 3 na última Avaliação Trienal da CAPES, a duplicação do número de bolsas e a desburocratização no processo de concessão das bolsas.

Entretanto, a concessão de cotas de bolsas do PDSE está vinculada à assinatura do Acordo de Cooperação entre a IES e a CAPES. Esse acordo tem validade de três anos e a sua renovação se dá mediante novo Acordo de Cooperação que considerará, essencialmente, o resultado da Avaliação Trienal da CAPES.

A duração da bolsa do PDSE pode variar de quatro (04) a doze (12) meses, é improrrogável e é estabelecida de acordo com o cronograma de execução proposto na candidatura. A bolsa constitui-se de seguro saúde, auxílio instalação, mensalidade e auxílio deslocamento (passagens de ida e retorno). Na Portaria Federal n. 141 de 14 de outubro de 2009, os valores da bolsa foram modificados, atendendo aos diversos níveis de formação. Nesse caso, a CAPES orienta que o valor da mensalidade é uma ajuda de custo, recomendando-se que o bolsista tenha reservas financeiras ou outra fonte de renda complementar para sua subsistência. No ano de 2010 a bolsa contemplava mensalidades de 1.300,00 euros, auxílio instalação de 550,00 euros (parcela única) e seguro saúde de 350,00 euros (para o período da concessão da bolsa).

Para ser contemplado com uma bolsa PDSE e não infringir as normas da CAPES é preciso ser organizado em todo o processo: no envio correto da documentação para a candidatura; no envio imediato da documentação póschegada ao país estrangeiro para dar início ao recebimento das mensalidades; e por último envio da documentação pós-retorno ao país de origem, relatório final e a ata da defesa da tese. Para uma maior organização e melhor compreensão do processo da bolsa PDSE dividiu-se em três fases: das intenções a conquista de uma bolsa; o estágio propriamente dito; e a última fase as contribuições teóricas do estágio ao desenvolvimento da tese. 


\section{PRIMEIRA FASE: DAS INTENÇÕES À CONQUISTA DA BOLSA PDSE}

As intenções de realizar um estágio de doutorado no exterior devem partir do próprio aluno no momento do ingresso no Programa e amadurecidas e planejadas conforme a condução da pesquisa. As intenções se transformam em propostas no decorrer das atividades curriculares, nas discussões e debates em eventos, nas contribuições teórico-metodológicas dos professores da banca de qualificação e fundamentalmente nas recomendações do Orientador. Na caminhada pela conquista de uma bolsa do PDSE é preciso organização e planejamento, pois para que a proposta se torne realidade existem diversos fatores exigidos pela CAPES.

O princípio desse processo de candidatura consiste em obter a carta de aceitação de um professor que assumirá a função de Co-Orientador do aluno no exterior. A obtenção desse aceite está atrelado há várias condições como, por exemplo, a disponibilidade do professor em acompanhar o aluno no período do estágio e da existência de cooperação internacional entre as Instituições brasileira e estrangeira. São condições que devem ser consultadas com um ou dois anos de antecedência. Outras condições analisadas pelo Co-Orientador são o projeto de tese e o cronograma de atividades a serem desenvolvidas durante o estágio.

A escolha do Co-Orientador pode ser indicada pelo Orientador, porém, o contato e aproximação com o possível Co-Orientador no exterior é realizada pelo aluno. Nesse aspecto, um dos canais de aproximação é a organização de eventos com professores estrangeiros em visita ao Programa de Pós-Graduação em Geografia da Universidade Federal do Paraná (UFPR). O "Café Geográfico" evento organizado pelo Núcleo de Estudo de Espaços e Representações (NEER), vinculado a linha Território, Cultura e Representações, favoreceu algumas aproximações e aceites pelos professores para serem Co-Orientadores em suas Universidades.

Uma das principais mudanças do Programa PDEE para o PDSE é a comprovação da proficiência da língua estrangeira. Atualmente, exige-se uma carta do Orientador brasileiro e uma do Co-Orientador declarando que o aluno possui a proficiência necessária na língua estrangeira. Anteriormente, era obrigatória a comprovação de proficiência no idioma por meio de certificados como o TOEFL 
(Tese of English as Foreing Language) para a língua inglesa, DELE (Diploma de Espanhol como Língua Estrangeira) para a língua espanhola, para a proficiência da língua francesa exigia-se o Teste da Aliança Francesa, para a língua alemã o Certificado do Instituto Goethe e para a língua italiana exigia-se o Latu Sensu do Instituto Italiano de Cultura. Para outros países os candidatos deveriam apresentar certificados emitidos por Instituições oficialmente reconhecidas com a anuência do Co-Orientador. A dificuldade em cumprir essa exigência era um dos principais fatores de interrupção dos processos de candidaturas.

Definida a escolha do Co-Orientador, o planejamento do aluno deve considerar o calendário de candidatura (fluxo contínuo) e a compatibilização com o calendário letivo da Universidade que deseja realizar o estágio. Pois, ao contrário do Brasil, nos países europeus e muitos outros, as férias são nos meses de julho e agosto, e as atividades são interrompidas em meados de junho e retornam e meados de setembro. Em janeiro também é período de férias. Nesse sentido, devese considerar que nos períodos de férias as funções da Universidade param e muitos dos serviços essenciais ao bolsista como, por exemplo, o uso da Biblioteca e Restaurante Universitário são fechados. Outra preocupação, nesse período, é a redução do policiamento dentro do campus e nenhuma segurança no interior dos prédios.

A concessão da bolsa PDSE ao aluno de doutorado inicia com a seleção prévia no próprio Programa de Pós-Graduação em que está vinculado, cuja proposta é analisada por uma comissão que define se o aluno está apto a participar do processo de candidatura. Desse momento em diante todo o processo é via on-line. O aluno faz a inscrição com o envio dos documentos no site da CAPES, a PróReitoria de Pesquisa e Pós-Graduação (PRPPG) homologa a inscrição e envia a relação dos inscritos para a CAPES. A CAPES analisa os documentos e envia até 30 dias à PRPPG a carta de concessão da bolsa do aluno selecionado e a PRPPG comunica ao aluno e solicita que venha buscar a documentação. $O$ aluno envia as documentações finais e a CAPES emite a implementação da bolsa em até 15 dias úteis antes da viagem.

Atualmente, o processo de compra das passagens é de responsabilidade do bolsista que escolhe a agência de viagens de sua preferência. Nos anos anteriores a 
emissão dos bilhetes aéreos era feito por uma agência de viagens conveniada com a CAPES. Essa nova norma, entre outras, visa desburocratizar o processo, principalmente nas situações de prorrogação da data de ida e volta. Contudo, as datas devem respeitar a orientação da CAPES quanto ao início do estágio até o $15^{\circ}$ dia do primeiro mês e término no último dia do mês de concessão da bolsa. Quaisquer taxas provenientes das alterações de datas de ida ou retorno são custeadas pelo bolsista.

A partir desse momento a CAPES disponibiliza o acesso do bolsista ao Sistema de Acompanhamento de Bolsas no Exterior (SAC - Exterior), aonde o bolsista cadastra os dados do local de moradia e informações bancárias no exterior. Nesse sistema, o bolsista pode verificar a situação do processo, o extrato das mensalidades, o envio de documentos avulsos e a consulta dos formulários on-line. Com a implementação da bolsa, a CAPES disponibiliza um técnico para orientar o bolsista quanto aos procedimentos legais durante todo o período do estágio e esclarecer as dúvidas quanto à bolsa concedida.

\section{SEGUNDA FASE: O ESTÁGIO NA UNIVERSIDAD AUTÓNOMA DE MADRID}

O estágio sob a co-orientação do Professor Clemente Herrero Fabregat foi realizado no período de 15 de abril de 2011 a 27 de agosto do mesmo ano, nas dependências do Departamento de Didácticas Específicas, na Facultad de Formación de Profesorado y Educación, da Universidad Autónoma de Madrid (UAM). As propostas apresentadas no Plano de Atividades para o estágio foram previamente apreciadas e aprovadas por minha Orientadora Professora Salete Kozel e pelo Co-Orientador. O planejamento das atividades do estágio foi estruturado em três momentos: reconhecimento e compreensão da realidade local; aprofundamento teórico e atividades práticas e por último a formalização de aliança inter-institucional. 


\subsection{RECONHECIMENTO E COMPREENSÃO DA REALIDADE LOCAL}

O primeiro momento é o de maior apreensão, pois surgem as incertezas quanto a adaptação à cultura local e quanto a superação dos sentimentos de solidão e saudade da família e amigos. Nessa etapa é fundamental o apoio do CoOrientador para a adaptação à nova cultura, ao auxílio na questão da hospedagem, na orientação quanto ao uso dos meios de transporte e, principalmente, na organização documental comprobatória do início do estágio para envio a CAPES. Recomenda-se, ainda nos primeiros dias, a abertura da conta bancária para a CAPES providenciar o pagamento das mensalidades.

$\mathrm{Na}$ Espanha, existem diversas possibilidades de hospedagem que vão desde a locação de um imóvel ou somente de um quarto, alojamento da Universidade, albergues como a Casa Brasil e até mesmo a hospedagem em conventos ou seminários. Aconselha-se contatar previamente o estabelecimento desejado para assegurar a hospedagem durante o estágio, porém, para evitar imprevistos é recomendável realizar reservas em um hotel para os primeiros dias. Minha escolha de hospedagem foi o alojamento da própria Universidade (Residência Erasmus II), pela proximidade e pelos serviços oferecidos similares a de um hotel. $\mathrm{O}$ custo mensal do alojamento, quarto individual, era de 700 euros, aparentemente caro, mas foi uma das opções de hospedagem mais econômicas encontradas. $\mathrm{Na}$ Residência Erasmus há também quartos duplos ou triplos com custos bem inferiores, mas são reservados para estadias de longa duração.

O campus da UAM está há $15 \mathrm{~km}$ do centro de Madrid e apesar do isolamento geográfico é bem servido por transporte coletivo, como trens e ônibus. $O$ campus concentra as Faculdades de Ciências, Direito, Filosofia e Letras, Psicologia, Medicina, Formação de Professores e Educação, Escola Politécnica Superior, o Centro de Investigações Científicas (semelhante ao CNPQ daqui do Brasil). Há também diversas bibliotecas, alojamentos para estudantes e professores visitantes, complexo desportivo, restaurantes universitários, bancos, correios, farmácia e muitas áreas de estares espalhados pelos jardins. Ainda em construção encontra-se 
um grande centro comercial que contemplará lojas, cinemas e restaurantes para oferecer entretenimento à comunidade universitária.

Os primeiros dias de estágio foram de apresentações aos professores do Departamento, instalação em um gabinete, liberação de senhas para acessar as bibliotecas e telefones, criação de E-mail institucional e reconhecimento dos serviços oferecidos pela Universidade. Um dos serviços que se destaca é a "Oficina de acolhida aos estudantes e investigadores estrangeiros" um setor especializado em acolher e orientar os estrangeiros sobre a estrutura da Universidade, os serviços de atendimento médico, orientações sobre as atividades desportivas disponíveis aos estrangeiros, as atividades culturais da UAM nos finais de semana, orientações sobre obtenção de bolsas, estágios, atendimento psicológico, entre outras coisas.

A primeira reunião com o Co-Orientador para apresentar o "projeto de tese" foi transformada em uma banca de qualificação com cinco professores do Departamento com diferentes formações. Nesse momento percebeu-se que a coorientação seria compartilhada com outros professores do Departamento, para colaborar no desenvolvimento das interfaces dos conhecimentos. O Professor Clemente articulou as aproximações com os professores do Departamento e de outras Faculdades dentro da UAM. Os referenciais teóricos apreendidos eram discutidos nas orientações e aplicados na formação conceitual e metodológica da pesquisa.

Nessa perspectiva, as atividades propostas para o estágio no Plano de Atividades foram revistas, sendo substituídas por outras mais adequadas ao desenvolvimento da pesquisa, sem perder a essência das propostas iniciais. $\mathrm{Na}$ visão do Professor Clemente as reflexões teóricas só afloraram com o domínio epistemológico da Geografia, cujas abordagens geográficas possibilitam visualizar claramente as transformações ocorridas no meio urbano e rural. Com esse pensamento as co-orientações iniciaram com a leitura e discussão da obra Geografía y Educación: sugerencias didácticas (HERRERO, 1995), entre outras.

O primeiro momento de reconhecimento e compreensão da realidade local se consolidou com a adaptação ao método de orientação do Co-Orientador, aos vários recursos de pesquisa disponíveis na UAM, bem como na autonomia em 
Seção Multíplice - Relato de doutorado sanduíche

contatar outros pesquisadores e pesquisar nas diversas bibliotecas internas e externas ao campus.

\subsection{APROFUNDAMENTO TEÓRICO E ATIVIDADES PRÁTICAS}

No segundo momento do estágio concretizou-se o aprofundamento teóricometodológico e algumas atividades práticas. Com base na análise do "projeto de tese" apresentado, o Professor Clemente destacou que devido ao curto período de estágio seria recomendável delimitar a proposta de investigação. Elencaram-se dois conceitos fundantes relevantes para o desenvolvimento da pesquisa: paisagem e mapas mentais.

O estudo da paisagem iniciou-se por meio das ricas leituras sobre epistemologia da Geografia que possibilitaram situar essa categoria de análise nas correntes geográficas. O estudo sobre mapas mentais deu-se por meio de profundas leituras no campo da psicologia, descobrindo-se a valorização de aportes teóricometodológicos desenvolvidos por arquitetos e geógrafos no uso de mapas mentais como ferramenta de investigação da relação homem e o meio.

$\mathrm{Na}$ investigação conceitual sobre paisagem reconhece-se a valiosa contribuição da Professora Pilar Lacasta Reoyo, ministrante da disciplina de Geografia da Paisagem, do Departamento de Didácticas Específicas, responsável por situar o estudo da paisagem na Espanha. Recomendou leitura das obras dos geógrafos Eduardo Martínez de Pisón (1998, 2009), Joan Nogué (1985, 1992, 2009) e Roberto da Mata (2006), por serem referências obrigatórias no meio acadêmico espanhol. A Professora Pilar destacou o atual debate na comunidade acadêmica sobre a adesão da Espanha ao Convênio Europeu de Paisagem. Este Convênio foi firmado em Florença (Itália), no dia 20 de outubro de 2000, com a adesão inicial de 19 países (ESPANHA, BOE. n.31 Martes 5 febrero, 2008).

Nesse convênio, a paisagem desempenha um papel importante de interesse geral nos campos cultural, ecológico, ambiental e social, pois é considerada um dos principais recursos ao desenvolvimento da atividade econômica, da criação de empregos, implicando na proteção, gestão e ordenamento territorial. O objetivo desse convênio é salvaguardar e promover os ideais e princípios que são de 
patrimônio comum. Em 2008, havia ao todo 35 países membros desse convênio, apontando a crescente preocupação com a ação humana sobre a paisagem.

No aprofundamento conceitual e metodológico sobre mapas mentais reconhece-se a fundamental colaboração da Professora Elena Martín Pérez, ministrante da disciplina de Psicologia Cognitiva, do Departamento de Psicologia da UAM, responsável por situar a evolução do processo de desenvolvimento da representação espacial no indivíduo. Recomendou diversas leituras destacando as obras do Professor Juan Delval (Universidad Complutense de Madrid), Orientador de sua tese de doutorado.

Com o aprofundamento nas obras de Delval $(1985,2006)$ percebeu-se um extenso referencial teórico na constituição conceitual dos mapas mentais. Adotou-se para a pesquisa o conceito de mapas mentais proposto por Juan Delval (1985), ao considerar que os mapas mentais são representações do indivíduo sobre o mundo vivido. Os mapas mentais não são simplesmente uma cópia do real, porque supõem um esforço de assimilação e de elaboração da realidade que depende da idade do indivíduo e de sua maturidade espacial.

Considera-se uma das grandes contribuições desse estágio o levantamento de várias metodologias de interpretação de mapas mentais. Mesmo que alguns aportes metodológicos se detenham apenas a classificação dos mapas, a compreensão de diferentes processos de análise foi essencial para a proposição de um método de análise e interpretação dos mapas mentais na pesquisa. Entre os autores investigados destacam-se na década de 1960, Kevin Lynch (1997) e Lloyd Rodwin (1969); década de 1970, Peter Gould (1974) e Alexander W. Siegel (MARTÍN, 1997); década de 1980, Gary Trent Moore (1983); e por último na década de 1990, Constancio de Castro Aguirre (2004). Na primeira década do século XXI, tem-se a metodologia de Salete Kozel (2001), muito conhecida por pesquisadores brasileiros, e mesmo não sendo uma contribuição do doutorado sanduíche, torna-se relevante sua menção diante da exposição cronológica das metodologias nesse texto.

As propostas para as atividades práticas prevista no Plano de Atividades foram adequadas pelo Co-Orientador, transformando-as em aulas de campo com a participação de professores de outras formações. As aulas visavam aplicar a teoria 
discutida nas orientações às análises das diferentes realidades visitadas. Com essa perspectiva, as aulas de campo foram distribuídas em dois ambientes: rural e urbano. No ambiente rural, visitou-se algumas cidades no entorno de Madrid, discutindo-se a transformação da paisagem natural em cultural com o processo de ocupação humana. Destacou-se a dificuldade de discernir o rural do urbano devido a expansão urbana, da redução das áreas agrícolas, da forte especulação imobiliária sobre áreas que deveriam ser preservadas. No ambiente urbano, fez-se algumas leituras do espaço, no qual buscou-se compreender a legibilidade da paisagem urbana, da constatação da homogeneidade dos signos urbanos e da perda de identidade cultural. Refletiu-se em ambos ambientes visitados a importância de se identificar os signos que impactam e ressignificam a paisagem.

\subsection{FORMALIZAÇÃO DE ALIANÇA INTERINSTITUCIONAL}

O terceiro momento do estágio consistiu-se na formalização de aliança interinstitucional entre a UFPR e a UAM. Uma atividade com características administrativas, mas fundamental para assegurar a continuidade de projetos futuros. Organizou-se a documentação para firmar o acordo de cooperação mútua e ampla entre as duas Instituições, visando desenvolver o intercâmbio de professores e estudantes para o desenvolvimento de pesquisas científicas. Objetivou-se com esse acordo promover grupos de trabalho e programas comuns de curto, médio e longo prazo na área da Geografia Humanista-Cultural. Além de fortalecer o intercâmbio de informações bibliográficas e facilidade para o acesso e investigação em bibliotecas e laboratórios das respectivas Instituições. $O$ documento foi preenchido e encaminhado a secretaria do Programa de Pós-Graduação em Geografia da UFPR para as devidas providências.

$\mathrm{Na}$ UAM existem dois acordos de cooperação internacional com Instituições brasileiras: a Universidade Estadual de Ponta Grossa (UEPG) e a Universidade Regional do Noroeste do Estado do Rio Grande do Sul (UNIJUí). Verificou-se que um dos objetivos desses intercâmbios com Instituições brasileiras é conhecer o sistema educacional brasileiro. Na primeira quinzena do mês de junho de 2010, o Professor Clemente e mais três professores do Departamento foram a UNIJUí, 
fortalecendo o intercâmbio entre a UNIJUí e UEPG, visitaram as respectivas Universidades com objetivo de apresentar o projeto pedagógico de Bolonha, novo sistema educacional implementado na Espanha.

\section{TERCEIRA FASE: CONTRIBUIÇÕES TEÓRICAS DO ESTÁGIO À PESQUISA}

A fase de finalização do estágio de doutorado sanduíche é novamente um momento de apreensão, pois é um momento de reflexão e avaliação sobre as reais contribuições do estágio ao desenvolvimento da pesquisa. Reflexões que conduzem a revisão das etapas percorridas desde o início do estágio, num processo de autoavaliação e crítica. De análise das propostas do Plano de Atividades, dos acertos e erros, do que poderia ser melhorado. Mas, principalmente uma profunda reflexão das contribuições dessa experiência para a formação acadêmica e pessoal; do orgulho em ver os desafios superados em todas as fases do processo do estágio; dos laços de amizade construídos com pessoas de diferentes culturas; e fundamentalmente, do desenvolvimento do espírito crítico sobre os conhecimentos apreendidos.

Nesse momento é preciso comunicar a conclusão do estágio à CAPES enviando o relatório final (formulário online disponível no SAC - Exterior), informando resumidamente a auto-avaliação sobre o estágio e críticas e/ou sugestões sobre a bolsa concedida. Outro documento importante para envio à CAPES e inclusive à Coordenação do Programa de Pós-Graduação é o parecer de avaliação do estágio do bolsista emitido pelo Orientador e Co-Orientador. Comunica-se, fundamentalmente, se os objetivos propostos no Plano de Atividades foram atingidos e se o bolsista atendeu as exigências da CAPES dentro dos prazos previstos. As orientações do estágio foram concluídas com uma longa conversa aonde o Coorientador demonstrou preocupação em atender as expectativas do Plano de Atividades e ofereceu-se em colaborar na pesquisa depois do retorno ao Brasil.

Com certeza foram inúmeras e valiosas as contribuições teóricas do estágio ao desenvolvimento da pesquisa, na clarificação do que se propôs defender na tese. A contribuição de autores estrangeiros, do acesso as obras originais de alguns 
autores, enriqueceu a fundamentação teórica da pesquisa e possibilitou ousar na proposição de novos aportes metodológicos. Outra conquista pessoal foi o amadurecimento do espírito crítico e analítico sobre os referenciais usualmente conhecidos.

Em uma análise comparativa visualizam-se algumas aproximações com a experiência do estágio no exterior com as etapas do desenvolvimento da tese. $\mathrm{Da}$ experiência do estágio no exterior com a experiência com o estudo da paisagem cultural em áreas preservadas, do contato com o novo com o contato com as comunidades tradicionais caiçaras, da descoberta do desconhecido com a descoberta do mundo vivido das pessoas. Foi durante as reflexões teóricas no estágio de Doutorado Sanduíche que conseguiu-se responder a pergunta: Qual é a sua tese? Foi nesse momento que gerou-se o embrião das homonímias sígnicas da paisagem em áreas preservadas, termo proposto e defendido na tese (KASHIWAGI, 2011).

\section{CONSIDERAÇÕES FINAIS}

Nessas poucas linhas procurou-se atingir o objetivo desse artigo, apresentando as contribuições do estágio de Doutorado Sanduíche na condição de bolsista PDSE. A apresentação do processo vivencial na Universidad Autónoma de Madrid foi estruturada em fases, nas quais buscou-se mostrar os desafios e conquistas à formação do estudante. A exposição ordenada das etapas que constituem o processo do estágio visou facilitar a compreensão do leitor ou candidato a uma bolsa PDSE.

A essência das contribuições do estágio de Doutorado Sanduíche encontrase no amadurecimento conceitual teórico-metodológico, constatado na defesa dessa pesquisa, cujos professores destacaram a rica contribuição teórica obtida com a citação de autores estrangeiros desconhecidos pelos brasileiros. Outra contribuição positiva na formação acadêmica refere-se ao desenvolvimento do espírito crítico, ousadia e coragem. O contato com outros valores culturais, costumes, novas amizades também constituem-se em valiosas contribuições. 
Diante do exposto, conclui-se que são inúmeras as contribuições que um estágio de Doutorado Sanduíche no exterior pode proporcionar na formação acadêmica. Frutificadas por meio da determinação, persistência, paciência, equilíbrio emocional e acima de tudo coragem. Coragem para superar com sabedoria os momentos de solidão e isolamento necessários no processo de reflexão e amadurecimento intelectual durante o processo de construção da tese.

\section{REFERÊNCIAS}

BRASIL. Decreto Federal n. 29.741, de 11 de julho de 1951. Institui uma Comissão para promover a Campanha Nacional de Aperfeiçoamento de Pessoal de Nível Superior. Diário Oficial [da] República Federativa do Brasil, Rio de Janeiro, RJ, 11 jul. 1951. Disponível em: <http://www.senado.gov.br>. Acesso em: 01/9/2011.

Lei n. 8.405, de 9 de janeiro de 1992. Autoriza o Poder Executivo a instituir como fundação pública a Coordenação de Aperfeiçoamento de Pessoal de Nível Superior (CAPES) e dá outras providências. Diário Oficial [da] República Federativa do Brasil, Brasília, DF, 10 jan. 1992. Disponível em: <http://www.presidencia.gov.br>. Acesso em: 01/9/2011.

Decreto Federal n. 6.316, de 20 de dezembro de 2007. Aprova o Estatuto e - Quadro Demonstrativo dos Cargos em Comissão da Coordenação de Aperfeiçoamento de Pessoal de Nível Superior - CAPES, e dá outras providências. Diário Oficial [da] República Federativa do Brasil, Brasília, DF, 21 dez. 2007. Disponível em: <http://www.capes.gov.br>. Acesso em: 01/9/2011.

Portaria n. 96, de 27 de junho de 2011. Institui o Programa Institucional de Doutorado Sanduíche no Exterior (PSDE). Diário Oficial [da] República Federativa do Brasil, Brasília, DF, 28 jun. 2011. Disponível em: <http://www.capes.gov.br>. Acesso em: 01/9/2011.

CASTRO AGUIRRE, C. Mapas mentales. Navarra: Universidad Pública de Navarra, 2004.

DELVAL, J. El mecanismo y las etapas del desarrollo. Madrid: Servicios de Publicaciones del MEC, 1985.

El desarrollo humano. 7 ed. Madrid: Siglo XXI de España Editores, 2006.

ESPANHA, BOE. n.31 Martes 5 febrero, 2008 
Seção Multíplice - Relato de doutorado sanduíche

GOULD, P.; WHITE, R. Mental maps. New York: Penguin Books, 1974.

HERRERO FABREGAT, C. Geografía y Educación: sugerencias didácticas. Madrid: Huerga y Fierro, 1995.

KASHIWAGI, H. M. Representações da paisagem no Parque Nacional de Superagui: as homonímias sígnicas da paisagem em áreas preservadas. $272 \mathrm{f}$. Tese (Doutorado em Geografia) - Universidade Federal do Paraná, Curitiba, 2011.

KOZEL, S. T. Das imagens às linguagens do geográfico: Curitiba, a "capital ecológica". 310 f. Tese (Doutorado em Geografia) - Faculdade de Filosofia, Letras e Ciências Humanas, Universidade de São Paulo, São Paulo, 2001.

LYNCH, K. A imagem da cidade. Tradução Jefferson Luiz Camargo. São Paulo: Martins Fontes, 1997.

MARTíN, E. El desarrollo de la representación espacial. In: GARCÍA MADRUGA, J. A; PARDO LEÓN, P. (Org.) Psicología Evolutiva (Tomo II). Madrid: UNED, 1997. p. 231-253

MARTÍNEZ DE PISÓN, E. El concepto de paisaje como instrumento de conocimiento ambiental. In: Paisaje y Medio Ambiente. Salamanca: Hergar, 1998, p. 9-28.

Miradas sobre el paisaje. Madrid: Editorial Biblioteca Nueva, 2009.

MATA, R. Un concepto de paisaje para la gestión sostenible del territorio. In: MATA, R.; TARROJA, A. (Org.) El paisaje y la gestión del territorio. Barcelona: Diputació de Barcelona, 2006. p.17-40.

MOORE, G. T. El desarrollo del conocimiento del ambiente: revisión de la teoría constructicionista-interacional y alguns datos sobre las variaciones evolutivas intraindividuales. In: Revista Estudios de Psicología, Madrid, n. 14/15, p. 109-123, 1983.

NOGUÉ I FONT, J. Una lectura geogràfico-humanista del paisatge de la Garrotxa. Barcelona: Universitat Autonoma de Barcelona, Collegi Universitari de Girona, 1985.

El paisaje existencial de cinco grupos de experiência ambiental: ensayo metodológico. In: GARCÍA BALLESTEROS, A. (Org.) Geografía y Humanismo. Barcelona: Oikos-Tau, 1992. p. 87-96.

Entre paisajes. Barcelona: Àmbit Servicios Editoriales, 2009.

RODWIN, L. Planning urban growth and regional development the experience of the Guyana program of Venezuela. Massachusetts: MIT Press, 1969. 